\title{
Disorders of Ocular Movement in a Case of Simultanagnosia
}

BY

A. R. LURIA, E. N. PRAVDINA-VINARSKAYA and A. L. YARBUSS

[Reprinted from BraIN, Vol. 86, Part II, 1963, pp. 219-228]

MACMILLAN AND CO., LIMITED ST. MARTIN'S STREET, LONDON

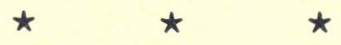

ST. MARTIN'S PRESS, INC.

175 FIFTH AVENUE, NEW YORK 10, N.Y. 1963 


\title{
DISORDERS OF OCULAR MOVEMENT IN A CASE OF SIMULTANAGNOSIA
}

$$
\text { BY }
$$

\author{
A. R. LURIA, E. N. PRAVDINA-VINARSKAYA AND A. L. YARBUSS \\ (Moscow)
}

\section{INTRODUCTION}

IN a previous paper (Luria, 1959), one of the present authors communicated a case in which marked disorders of "simultaneous perception" (simultanagnosia) resulted from bilateral occipital brain injury. As in earlier cases of the same type (Balint, 1909; Holmes and Horrax, 1919; Paterson and Zangwill, 1944; Hécaen and Ajuriaguerra, 1954) the patient was able to perceive only one object at a time irrespective of the angular size of its retinal image. This defect of perception was combined with severe impairment of oculomotor co-ordination-a kind of "optic ataxia"-and the patient was quite unable to perform manual operations based on the visual analysis of spatial relations. The question arises as to whether this "optic ataxia" is directly due to the perceptual derangement or whether it constitutes an independent executive disability. We shall attempt to answer this question in the present paper.

A simple method of photographic recording of eye movements was devised by one of the present authors (Yarbuss, 1961). A rubber bulb carrying a small mirror was attached to the cornea and a thin pencil of light thrown on to the mirror and reflected on to a sheet of photographic paper (fig. 1). This simple technique permits scanning movements of the eyes to be registered in a variety of everyday tasks, e.g. looking at a

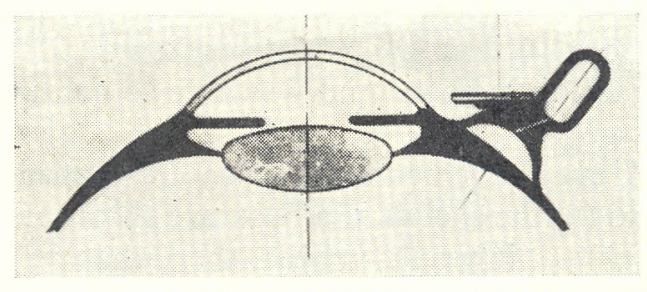

FIG. 1.-Method of recording eye movements. 
picture. An illustration of the pattern of eye-movements in a normal subject whilst observing a head portrait is shown in fig. 2 and a complex picture in fig. 3, A and B, Plate XXVIII.

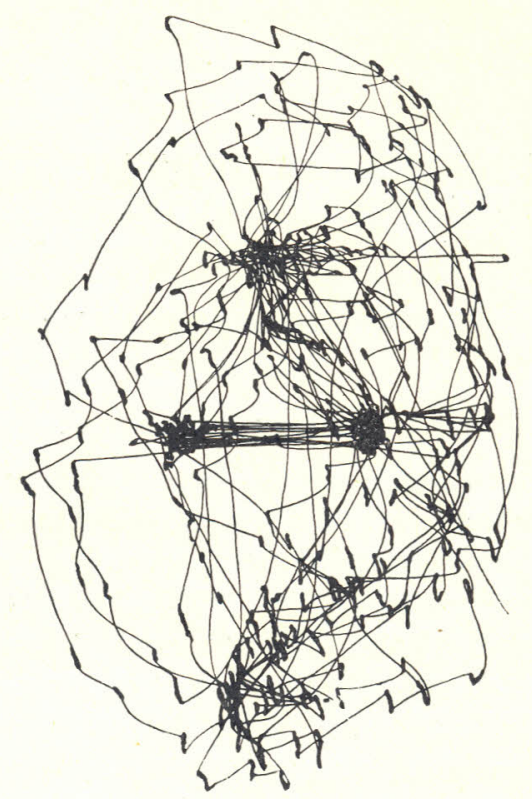

Fig. 2.-Saccadic eye movements in perception of a portrait by a normal subject.

\section{Eye Movements in Cases with Restricted Visual Fields}

It is well known that patients with severely restricted fields following lesions of the optic nerve (opto-chiasmatic arachnoiditis) show no gross defect in perception, spatial orientation or oculomotor control. These patients are apparently able to compensate for their "tubular vision" by active tracking and saccadic movements of the eyes and the perceptual field in consequence preserves its normal structure. A photographic recording of eye movements was undertaken in one such case.

D......, a woman aged 40, had a severe restriction of the visual fields in both eyes as a result of an opto-chiasmatic arachnoiditis. The fields were limited to about $10^{\circ}$ but in spite of her "tubular vision" the patient retained her orientation in space and was able to continue with her work as an archivist.

The patterns of eye movements shown by this patient when perceiving (A) a rectangle, and (B) the sketch of a bust, are shown in fig. 4 and present no gross abnormality. It would appear, then, that peripheral restriction of the visual field in the absence of simultanagnosia produces no gross defect of perception or oculomotor disability. 


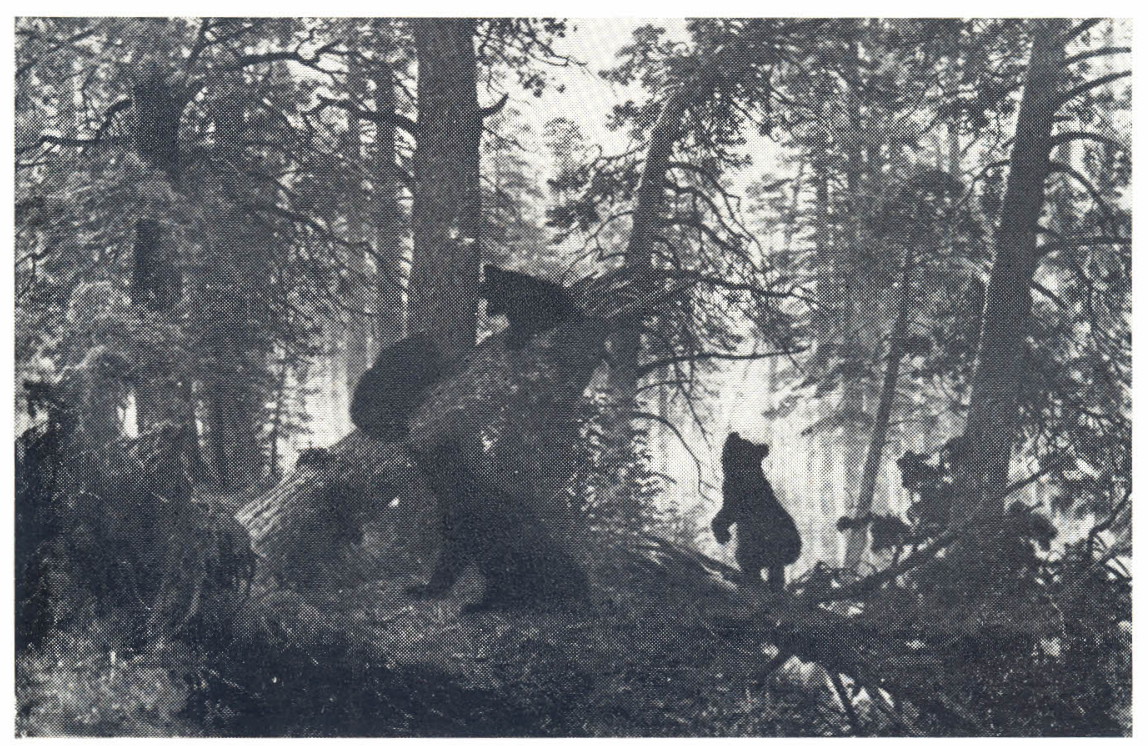

A

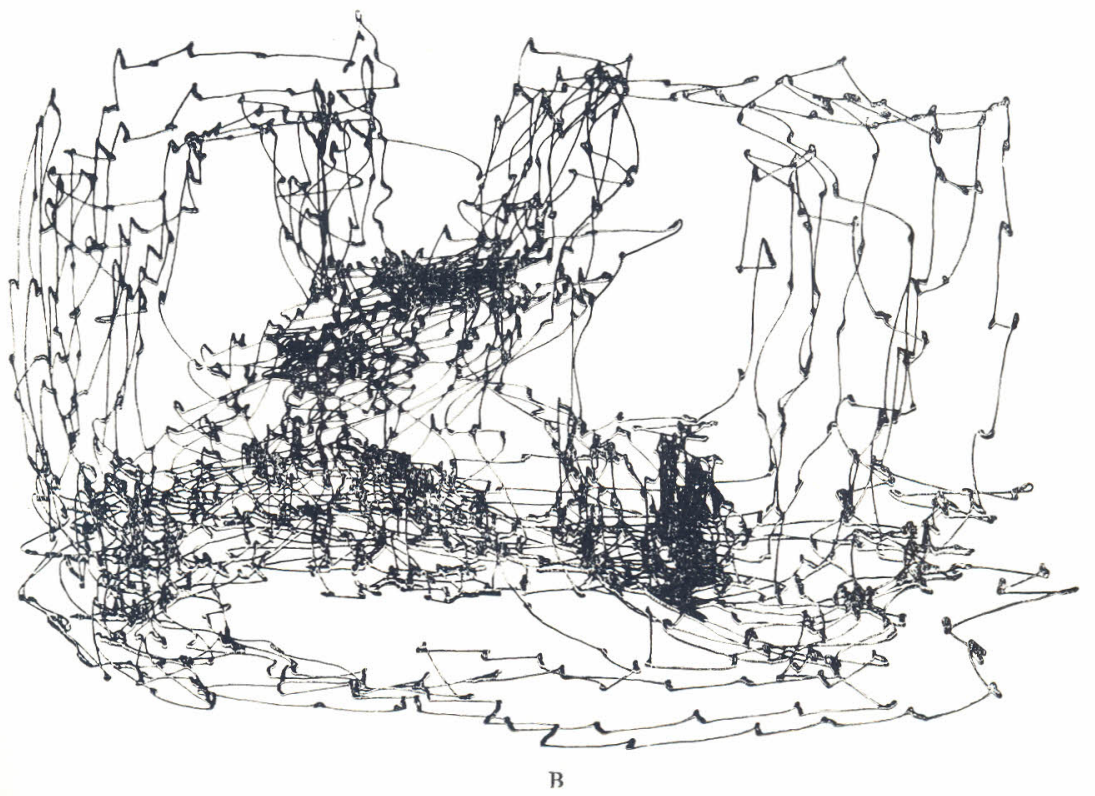

FIG. 3.-Saccadic eye movements (B) in perception of picture shown in A. 


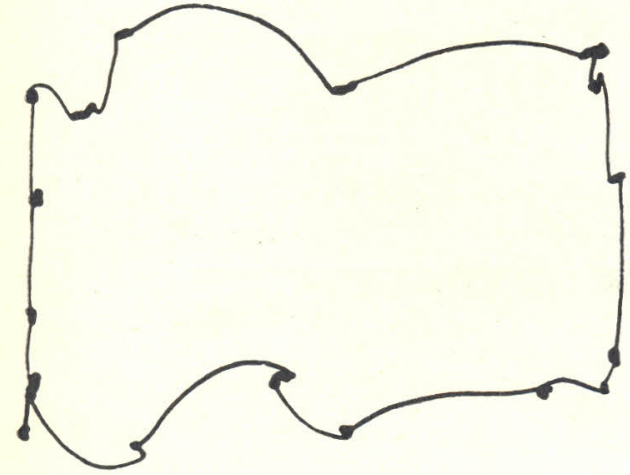

A

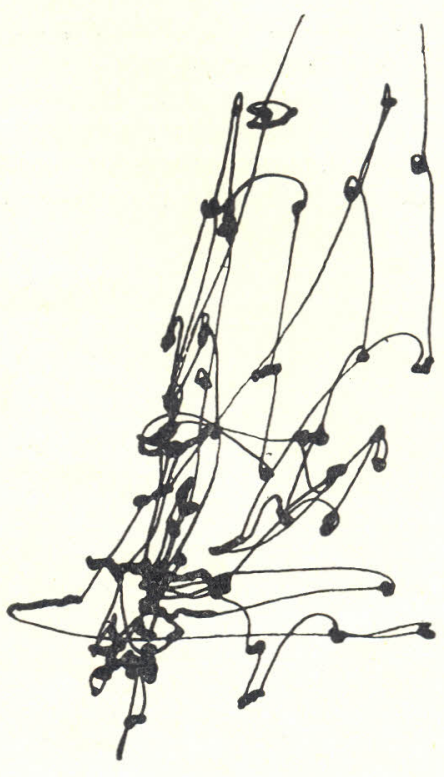

B

FIG. 4.-Eye movements in perception of (A) a rectangle, and (B), a portrait, by a patient with severe restriction of the visual fields.

\section{Eye Movements in a CASE of Simultanagnosia}

The patient, I. R., a book-keeper aged 48, was admitted to the Bourdenko Neurosurgical Institute in September 1959, complaining of headaches and visual difficulties which he found impossible to describe.

In February 1958 he had first noticed headaches and difficulty in dressing. In April 1959 he noted difficulty in reading. It seemed that he could see only individual letters, rarely whole words. These defects gradually increased in severity until he became virtually unable to perceive more than one object at a time and his orientation in space became gravely disturbed. On the other hand, his emotional attitude and orientation in time were presarved and he was extremely co-operative and critical. No marked defect in intellectual abilities (apart from special defect in simultaneous operations) was ascertained.

Visual acuity was 1.0 in both eyes. Fundi normal. There was a disturbance of optokinetic nystagmus to both sides, particularly the right. Visual fields were almost impossible to test on account of the severe perceptual disability. Slight pyramidal signs on both sides and a slight defect of discriminative sensibility in the right hand.

Blood pressure was $140 / 90$. Wassermann reaction negative. There was 0.60 per cent albumin on the C.S.F. with cythosis 12/3. Lange reaction 332210 . CSF pressure 200 c.c. of water.

Skull X-ray showed no significant features. On EEG examination, alpha rhythm was absent on both sides and some abnormality was present in the occipital regions.

No conclusive neurological diagnosis was possible. A tentative diagnosis was made of endoarteritis with pathological changes in both occipital lobes.

The patient's most important symptom was the bizarre disturbance of visual perception. In spite of adequate visual acuity he behaved in ordinary life like a 
blind man. When ascending a staircase, he could not perceive a person approaching him and avoid a collision. He could not co-ordinate movement with visual perception and not uncommonly closed his eyes in order better to control his actions. $\mathrm{He}$ was unable to read on account of an inability to follow the lines and a tendency to perceive isolated letters or words on different lines. When writing, he was again unable to follow the lines and often superimposed letters and words (fig. 5).
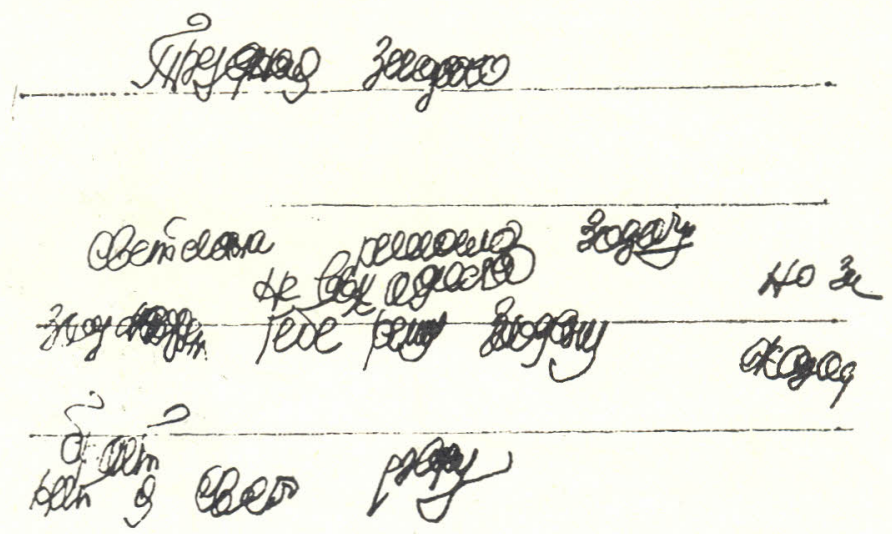

FIG. 5.-Sample of writing in a case of simultanagnosia.

When observing a complex scene, the patient always stated that he saw but a single object. Thus looking out of the window of a car, he was able to see only one car, then a second, then a third, but always one at a time. ("I know there are many but I only see one.") When looking out of the window of a house, he saw the entrance of the house opposite but not the snow that was falling at the time. When he saw the snow he was no longer able to see the house opposite. The picture was thus very similar to that described by Balint (1909) and more recently by one of the present authors (Luria, 1959).

Tachistoscopic tests.-When drawings of single objects (e.g. carrot, fork, circle, cross) were presented in a tachistoscope (from $6^{\circ}-8^{\circ}$ to $15^{\circ}-20^{\circ}$ ) they were adequately recognized, irrespective of their size. When drawings of two such objects were presented, on the other hand, the patient was only able to recognize one of them, despite repeated exposure.

Drawing tests.-If the patient were required to draw a line following the contour of a single geometrical figure (fig. 6, b and c), his performance was very defective. He likewise found great difficulty in indicating the centre of a circle, dividing it into two equal halves, or drawing the outline of a face given the features or placing the features in an outline-face provided him (fig. 6, $\mathrm{f}$ and $\mathrm{g}$ ). Free drawing was likewise grossly impaired (fig. 7). These performances illustrate well the gross defect in visuomotor co-ordination.

Eye movement studies.-Fixation of a single light source in an otherwise dark field showed no disturbance. If the light were set into regular motion, tracking movements of the eyes were accomplished normally (fig. 8). The position, however, was very different when eye movements involved in visual searching were recorded: If, for example, the patient were required to shift his fixation from one point to a second (the distance between them being $5^{\circ}$ ) a highly disorganized, ataxic kind of record was obtained (fig. 9). In observing a quadrilateral (fig. 10), a similarly disorganized record was forthcoming. Finally, in observing a portrait (the same as 
Drawing a circle
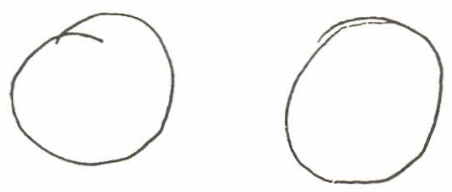

(a)

Tracing a circle

'It is difficult: I don't see at the same time both - the pencil and

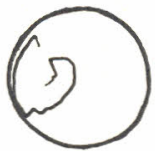
the circle. The hand does not

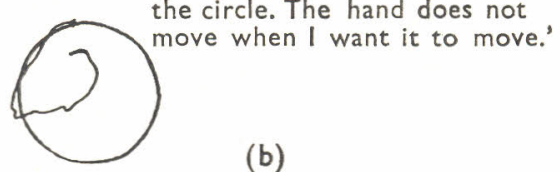

(b)

The drawing of a circle inbetween two already drawn circles

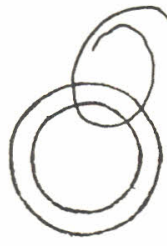

(c)

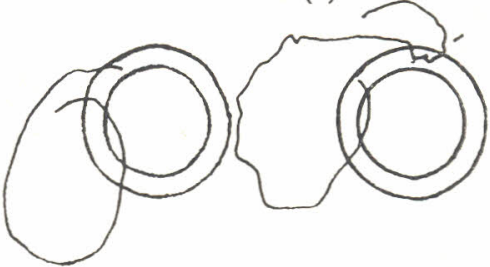

Place a point in the centre of a circle

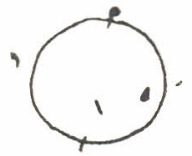

(d)

Draw the outlines of a face

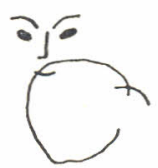

Divide a circle into two halves

(e)

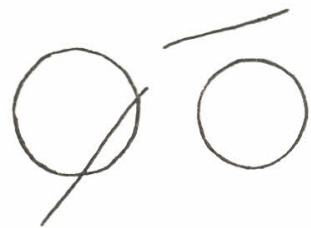

Draw the eyes, eye brows, nose and mouth

(g)

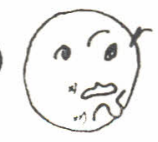

x) mouth

*x) nose

FIG. 6.-Samples of drawing in a case of simultanagnosia. a, drawing of a circle; $\mathrm{b}$ and $\mathrm{c}$, tracing contours of circle; $\mathrm{d}$, placing a dot in centre of a circle; e, bisecting circles; $f$ and $g$, completing drawings of a face. 
Drawing

Elephant

head

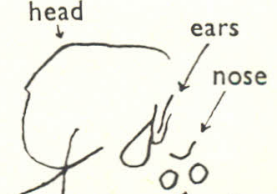

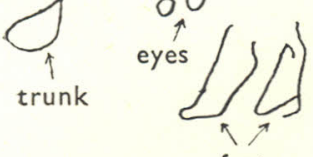

feet
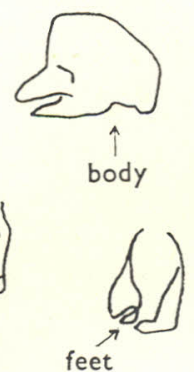

Copying
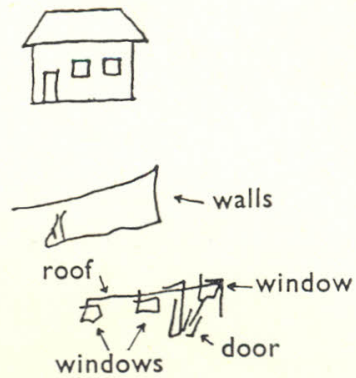

(b)

'I can visualize it well ... but

my hands don't move properly'

(a)

FIG. 7.-Drawings of (a), elephant; (b), house.

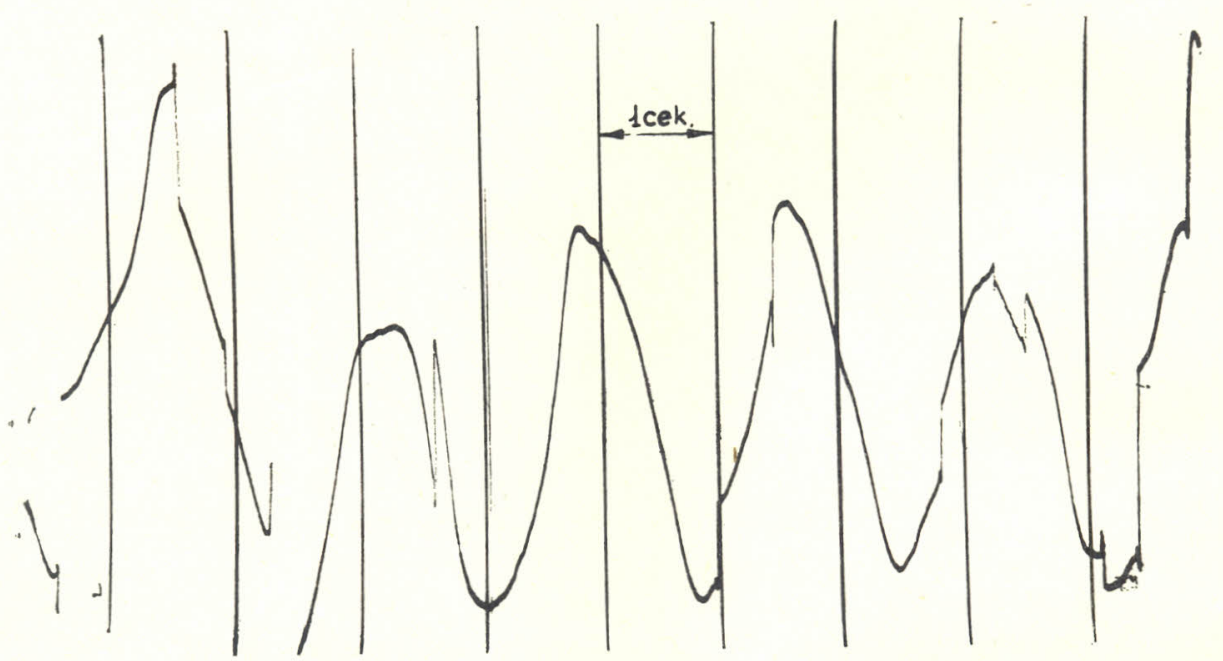

FIG. 8.-Eye movements in tracking a single light source.

that used in obtaining the record shown in fig. 2), no regular tracing of the contour and exploration of the features by the eyes can be seen (fig. 11). Although the patient immediately perceived a face, he was unable to concentrate his gaze on the separate details for, when a detail was perceived, its relation to the whole was immediately lost. It is small wonder, then, that eye movements became chaotic.

Effects of anticholinergic drugs.-It was stated by Luria (1959) that certain pharmacological agents could produce an important change in the pattern of simultanagnosia. We repeated the experiment in the present case. 1 c.c. of a 0.25 
per cent solution of galentamine (an anticholinergic drug extracted from the root of a Caucasian plant, equivalent to prostigmine) was injected subcutaneously. About forty minutes later, there were marked changes in the patient's visual behaviour: he became able to perceive two figures simultaneously, to place a dot in the centre of a circle, or draw a circle round a given point (fig. 12). His reading improved and there was a definite improvement in visual tracking. These effects lasted for about 40-60 minutes.

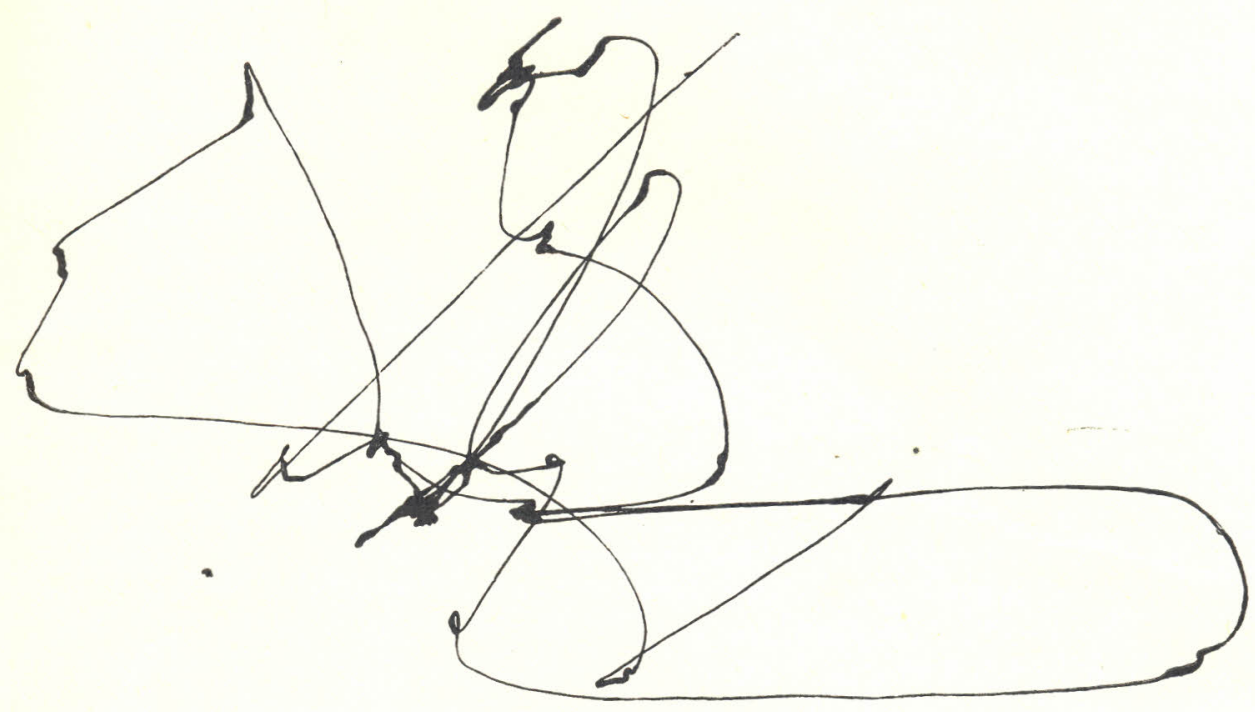

FIG. 9.-Eye movements in shifting fixation between adjacent points.

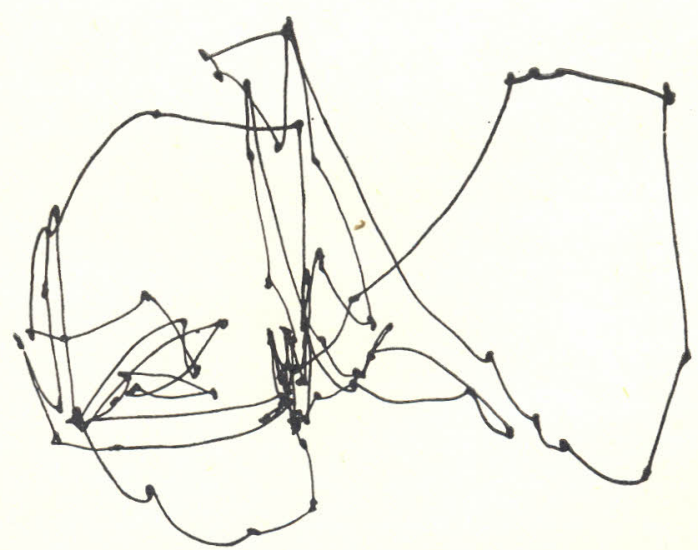

FIG. 10.-Eye movements in tracing the contour of a rectangle. 


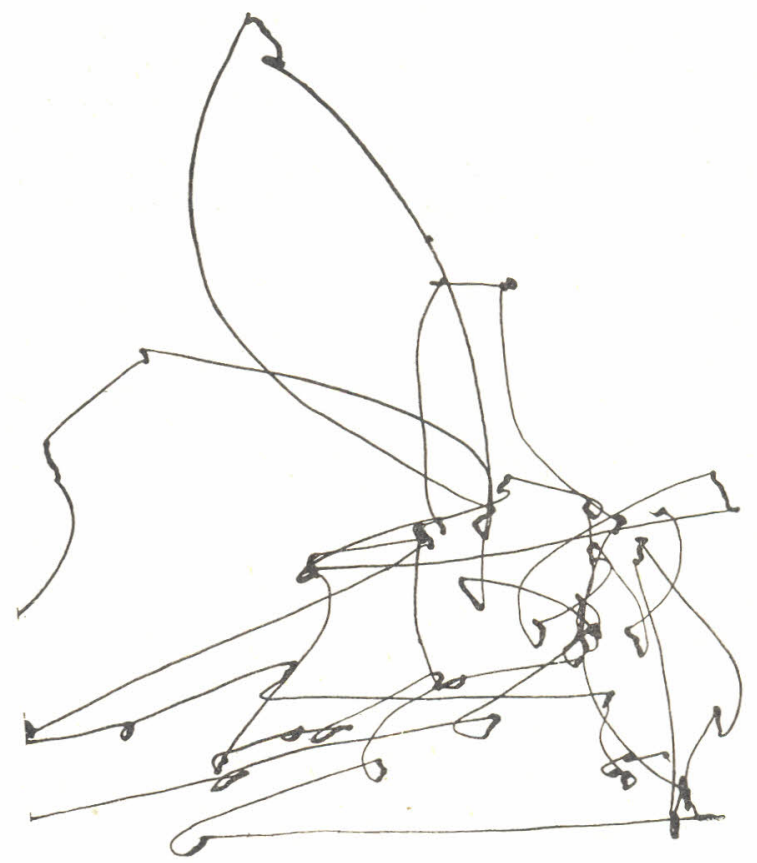

FIG. 11.-Eye movements in observing a portrait.

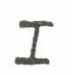

II

Place a point in the centre of a circle
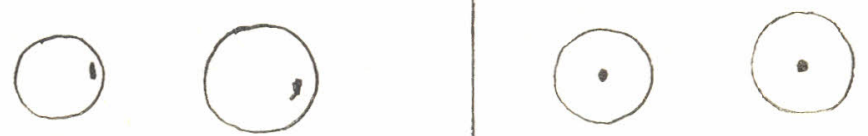

Draw a circle around a point<smiles>C1=CCCCCCC1</smiles>

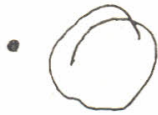

(a)

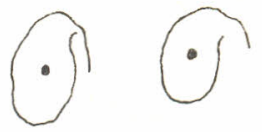

(b)

FIG. 12.-Effects of galantamine on visuomotor performance. Placing a dot in centre of circle (a) before and (b) after injection. 


\section{Discussion}

The data in this case indicate two very closely related symptoms: on the one hand, limitation of visual attention (Holmes, 1919) or "piecemeal perception" (Paterson and Zangwill, 1944); on the other hand, optic ataxia and severe disorganization of oculomotor response.

Two hypotheses may be put forward. First, that the oculomotor disorder represents an independent executive disability; and secondly, that it arises as a consequence of the perceptual restriction. As regards the first hypothesis, i.e. a possible disturbance of efferent control of eye movements following bilateral occipitoparietal injury and leading to impaired motor organization of the gaze, it must be admitted that the evidence is scarcely convincing. As we have seen, the patient was able to track a single moving object with the eyes and under these conditions oculomotor performance was essentially normal. It is therefore much more probable that the disability is secondary to the perceptual loss. As Holmes (1938) pointed out, "It is impulses of foveal origin which determine reflex fixation. On the other hand, the chief function of the peripheral parts of the retina when an image excites them is to bring about such movements of the eyes that the image falls on the fovea." It would seem that in cases in which visual attention is narrowed to the perception of a single object normal relations between foveal and peripheral vision are impaired. The absence of appropriate signals from the peripheral visual fields gravely impairs the visual orienting reflex and images falling in the periphery of the retina are thus no longer brought into central vision. This leads to the chaotic character of the ocular searching movements recorded in our experiments.

In keeping with the tentative interpretation offered in an earlier paper (Luria, 1959), it may be concluded that simultanagnosia and its related disturbance of oculomotor control arise from a process of inhibition in the occipital cortex which results in a restriction of excitation to a single point (Pavlov, 1955). In consequence, normal functional relations between peripheral and central vision in the control of fixation and in exploratory movements of the eyes are grossly disturbed. It will be necessary, however, to repeat the observations on a larger number of cases before final conclusions can be drawn.

\section{Summary}

(1) A method of photographic recording of eye-movements is described and its application to the study of neuropathological disorders considered. It is pointed out that restriction of the visual fields associated with optic nerve lesions produces neither gross disorder of perception nor significant defect in the patterns of eye movements associated with perception. 
(2) A case with severe defect of "simultaneous perception" is described. In this case, tracking movements of the eyes in following a single light source were unimpaired but gross defects were evident in visual scanning. It is concluded that the disorder in eye-movement control is probably secondary to the restriction of "visual attention" and reflects derangement of the normal relations between peripheral and central vision in the control of ocular fixation.

\section{REFERENCES}

Balint, R. (1909) Mschr. Psychiat. Neurol., 25, 51.

Hécaen, H., and Ajuriaguerra, J. De (1954) Brain, 77, 373.

Holmes, G. (1919) Brit. med. J., 2, 230.

- (1938) Brit. med. J., 2, 107.

- and Horrax, G. (1919) Arch. Neurol. Psychiat. Chicago, 1, 385.

LuRIA, A. R. (1959) Brain, 82, 437.

Paterson, A., and Zangwill, O. L. (1944) Brain, 67, 54.

Pavlov, I. P. (1955) Selected Works. Moscow.

YARBUSS, A. L. (1961) Biofizika. Moscow, 6, 207. 
Printed in England

by

STAPLES PRINTERS LIMITED

at their

Tabernacle Street. London. E.C.2 establishment 